\section{Effect of Nitrogen Fertigation on First-year Pecan Seedling Growth}

\author{
Patrick Conner ${ }^{1}$
}

\begin{abstract}
ADDITIONAL INDEX WORDS. roots, stems, shoots, fertilizer, propagation, budding
Summary. Pecan (Carya illinoinensis) seedling rootstocks require several years of growth in the nursery before they are large enough to graft. In this experiment, first-year pecan seedlings were fertigated with varying amounts of calcium nitrate in an attempt to stimulate growth rates. Pecan seedlings were fertigated every 2 weeks from May through October for a total of 10 applications. Total amounts of nitrogen $(\mathrm{N})$ applied by fertigation were $0,4,10,20$, and $40 \mathrm{~g}$ of $\mathrm{N}$ per seedling. Leaf samples were taken after the fourth and tenth fertigations, and leaf elemental concentration was affected by fertigation rates. Seedling height and caliper were measured monthly. Seedling caliper continued to increase throughout the experiment, whereas height increase stopped in September. Seedling height and caliper were unaffected by $N$ fertigation except for the $N$ rate of $40 \mathrm{~g}$, which suppressed seedling growth. These results suggest that the $\mathbf{N}$ needs of the seedlings were met by a preplant application of $50 \mathrm{lb} /$ acre $\mathrm{N}$ applied as $10 \mathrm{~N}-4.4 \mathrm{P}-8.3 \mathrm{~K}$.
\end{abstract}

$\mathrm{P}$ ecan is a highly heterozygous outcrossing species, which shows wide variation in nut and tree quality when propagated from seed. The majority of pecan nuts are harvested from orchards of clonally propagated cultivars, although significant production is still obtained from seedling orchards and native groves [U.S. Dept. Agr. (USDA), 2005]. Most pecan trees are produced in field nurseries. Pecan cultivars are budded or grafted onto seedling rootstocks and then are dug and sold as bareroot trees. Pecan seedlings generally require two to three seasons of growth before their diameter is large enough to be grafted or budded. At least one more season of growth is incurred before trees are dug and sold. Thus, at least 3 to 4 years are required in the nursery before a saleable tree is produced, increasing the cost of the product and tying up land in the nursery. If sufficient growth could be produced the first year in the nursery, seedlings could be grafted in the first winter, reducing the time needed to produce a saleable tree.

Propagation of pecan trees is directly influenced by the growth pattern of pecan seedlings. Pecan seedling growth begins with the root, which will extend into the soil $30 \mathrm{~cm}$ or more before the hypocotyl emerges (Sparks, 2005). Shoot growth in

University of Georgia-Tifton Campus, Horticulture, 4604 Research Way, Tifton, GA 31793

${ }^{1}$ E-mail: pconner@uga.edu. young seedlings lags behind root growth, and leaf number of 'Curtis' seedlings seems to be predetermined at a maximum of 11 to 13 leaves per seedling (Sparks, 2005). Stem dry weight may comprise as little as $12 \%$ of the total dry weight of a l-year-old pecan seedling (White, 1982). Once this maximum has been reached, no method has been developed to allow the seedling shoot to continue growing the first year (Worthington, 1997). In contrast, the root continues to grow and can reach $2 \mathrm{~m}$ in length by the end of the first season (Sparks, 2005).

Nitrogen fertility levels can have a profound effect on tree seedling growth. Shortening rotation time by maintaining high fertility is a common method of increasing nursery productivity. Nitrogen $(\mathrm{N})$ in particular is relatively inexpensive and greatly stimulates growth in red oak (Quercus rubra) and red maple (Acer rubrum) seedlings (Larimer and Struve, 2002). Nitrogen fertigation resulted in a twofold height increase for red oak seedlings and over a threefold height increase in red maple cuttings as compared with no $\mathrm{N}$ treatments (Larimer and Struve, 2002). Timing of $\mathrm{N}$ applications may be as important as the total amount of $\mathrm{N}$ applied. Kormanik et al. (2003) found that applications of $\mathrm{N}$ at intervals of 10 to $12 \mathrm{~d}$ maintained continuous elongation in first-year red oak and white oak (Quercus alba) seedlings. Sparks and Baker (1975) found that moderate amounts of ammonium nitrate stimulated growth of second-year pecan seedlings but that higher rates suppressed growth.

Nitrogen levels cannot only influence seedling growth rates, but can also affect shoot:root ratios, which influence seedling quality (Harris, 1992; Larimer and Struve, 2002). High levels of fertility typically cause plants to direct more growth to the aboveground portions of the plant. Competitor species like red maple have been shown to direct more resources to leaves and shoots in nutrient-rich environments (Larimer and Struve, 2002). This allows shoot growth to be maximized giving this shade-intolerant species an important survival advantage. In contrast, red oak, a stress tolerator species, responded to higher $\mathrm{N}$ levels with proportionally increased root and shoot growth (Larimer and Struve, 2002). Pecan is a shade-intolerant species, but pecan seedlings can exist in the understory in varying states of arrested growth for several years until a disturbance produces a light gap (Sparks, 2005). This experiment was undertaken to determine if the frequent application of $\mathrm{N}$ could increase shoot growth of first-year pecan seedling shoots as was seen in red oak and white oak (Kormanik et al., 2003). Increased growth of first-year pecan seedlings would be a valuable tool to decrease 
the long turnover time needed to produce grafted pecan trees.

\section{Materials and methods}

Open-pollinated seed of the USDA selection 70-6-15 ('Kiowa' $x$ 'Desirable') was used as the seed stock to produce seedlings. Seed was soaked in running water for $2 \mathrm{~d}$ and then stratified in damp cedar shavings for $90 \mathrm{~d}$ at $4{ }^{\circ} \mathrm{C}$. Seed was then transferred to $32{ }^{\circ} \mathrm{C}$ to initiate germination, and seed with cracked shells and an emerging radical was used to plant the experiment. Seed was planted in the first week of Mar. 2005.

The experiment was conduced at Tifton, GA, on a Tifton loamy sand (Ultisol Plinthic Paleudults: fine loamy, siliceous, thermic). The $\mathrm{pH}$ of the field was adjusted to 6.5 with dolomitic limestone on 2 Feb. 2005. The field was preplant-amended with $50 \mathrm{lb} /$ acre of $10 \mathrm{~N}-4.4 \mathrm{P}-8.3 \mathrm{~K}$ with micronutrients ( $2 \%$ magnesium, $12 \%$ sulfur, $0.07 \%$ boron, $0.25 \%$ manganese, $0.25 \%$ zinc) broadcast over the entire plot and incorporated into the soil. Soil was bedded into 3 -ft-wide beds and covered with white on black 1.25-mil polyethylene mulch. Rows were spaced $5 \mathrm{ft}$ apart and seedlings were planted $\mathrm{l} \mathrm{ft}$ apart within the rows. Treatments were arranged in four 100 -ft-long rows in a northsouth orientation. Insecticides were applied equally to all seedlings to control pecan bud moth (Gretchina bolliana) and leaf phylloxera (Phylloxera notbilis). Weeds between rows were removed by hand as needed.

Nitrogen fertigation treatments were applied by placing two $4-\mathrm{L} \cdot \mathrm{h}^{-1}$ pressure-compensated emitters at each seedling. One emitter was attached to a water line and applied only unamended water. The other emitter was attached to a fertigation line, which applied a $0.2 \% \mathrm{~N}$ solution of calcium nitrate $\left(\mathrm{CaNO}_{3}\right)$. The timing of the applications was varied so that five different amounts of $\mathrm{N}$ were applied to the treatments while keeping the total amount of water applied constant. In the first treatment, the water line was on for $30 \mathrm{~min}$ and no $\mathrm{N}$ was applied. In the second treatment, the fertigation line was on for $3 \mathrm{~min}$ and the water line was on for $27 \mathrm{~min}$ so that $0.4 \mathrm{~g} \mathrm{~N}$ was applied. In the third treatment, the fertigation line was on for $7.5 \mathrm{~min}$ and the water line was on for $22.5 \mathrm{~min}$ so that $1.0 \mathrm{~g} \mathrm{~N}$ was applied. In the fourth treatment, the fertigation line was on for $15 \mathrm{~min}$ and the water line was on for $15 \mathrm{~min}$ so that $2.0 \mathrm{~g}$ of $\mathrm{N}$ was applied. In the fifth treatment, the fertigation line was on for $30 \mathrm{~min}$ so that $4.0 \mathrm{~g}$ of $\mathrm{N}$ was applied and the water line was not turned on. The first application was applied on 20 May 2005 at which time most seedlings had three to four expanded leaves. Nitrogen applications were thereafter applied every $14 \mathrm{~d}$ with the final treatment applied on 23 Sept. 2005 for a total of 10 applications.

Treatments were arranged in a randomized block design with nine replications per treatment. Each replication consisted of nine seedlings with all measurement and leaf analysis coming from the five seedlings in the center of replication. Stem caliper at soil level and seedling height were measured on 20 May 2005 and then at every other $\mathrm{N}$ application. The final measurement was taken on 7 Oct. 2005, 2 weeks after the last $\mathrm{N}$ application. Leaf samples for nutrient analysis were taken on 15 July 2005 and 7 Oct. 2005, 2 weeks after the fourth and tenth $\mathrm{N}$ applications, respectively. Samples were taken by removing the two apical fully expanded leaves from each of the center five seedlings and grouping them together for a single sample. Five replications of each $\mathrm{N}$ treatment were randomly chosen for leaf analysis with the same replications being analyzed for the second analysis. To determine root and stem dry weights, seedlings were dug in Jan. 2006 and the roots were carefully washed to remove adhering soil. Root caliper was measured $4 \mathrm{~cm}$ below the soil line. Stems and roots were labeled, separated, and air-dried for several weeks before weighing. Fertigation effects on seedling growth and leaf elemental concentration were statistically analyzed by analysis of variance with mean separation by Duncan's multiple range test using SigmaStat (SPSS, Chicago) statistical software. Associations between seedling measurements were determined by Pearson product moment correlation coefficients using mean values of replications across treatments. For associations with stem height and stem caliper, only the final measurements taken on 7 Oct. 2005 were used in correlation analysis.

\section{Results and discussion}

Pecan nursery operations are hampered by the relatively slow growth made by first-year pecan seedlings, which often necessitates a second year of culture in the nursery before they are large enough to graft. Kormanik et al. (2003) found that the frequent application of high rates of $\mathrm{N}$ stimulated the growth of white oak and red oak first-year seedlings and prevented early bud set in the nursery, and suggested that this protocol may be successful in increasing first-year growth rates in a number of hardwood species. In contrast, Sparks and Baker (1975) found that high levels of $\mathrm{N}$ resulted in a reduction in pecan seedling growth. However, the Sparks and Baker experiment was conducted on secondyear seedlings and took place in the greenhouse in a relatively artificial growing environment. The current experiment was undertaken to determine if frequent applications of $\mathrm{N}$ could increase shoot growth in firstyear pecan seedlings as was seen in red oak and white oak.

The caliper of seedlings of all treatments continued to increase throughout the measurement period (Fig. 1). Seedling caliper was unaffected by $\mathrm{N}$ fertigation at any measurement date except 12 Sept., when the highest $(40 \mathrm{~g}) \mathrm{N}$ rate resulted in a reduction in caliper as compared with the 0 and $10 \mathrm{~g}$ of $\mathrm{N}$ treatment (Fig. 1). Similarly, seedling height was unaffected by $\mathrm{N}$ fertigation until the last two measurements (Fig. 2). In September, the $40 \mathrm{~g} \mathrm{~N}$-treated seedlings were shorter than the $10 \mathrm{~g}$ $\mathrm{N}$-treated seedlings. In October, the $40 \mathrm{~g} \mathrm{~N}$-treated seedlings were shorter than the $0 \mathrm{~g} \mathrm{~N}$ and $10 \mathrm{~g} \mathrm{~N}$-treated seedlings. The height of the seedlings of most treatments increased until September, after which there was little change (Fig. 2). However, the $40 \mathrm{~g}$ N treatment stopped elongation after the August measurement. Nitrogen fertigation did not affect dry weight except that the $40 \mathrm{~g} \mathrm{~N}$-treated seedlings were significantly lower than the $0 \mathrm{~g}$ and $10 \mathrm{~g} \mathrm{~N}$-treated seedlings for root, shoot, and total dry weight (Fig. 3).

Growth measurements taken after the end of the growing season were all highly correlated (Table 1). Root caliper is more important to the 


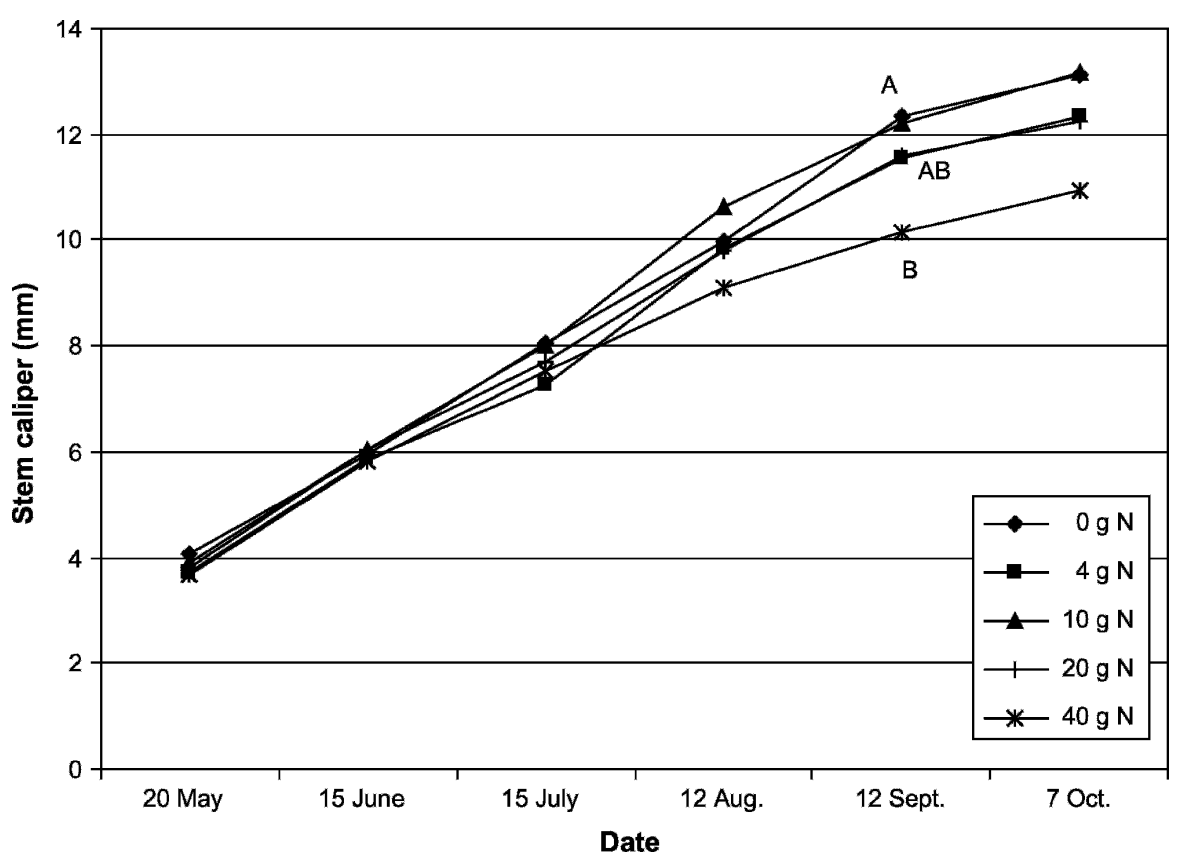

Fig. 1. Effect of nitrogen $(\mathrm{N})$ fertigation on first-year pecan seedling stem caliper. A total of $0,4,10,20$, or $40 \mathrm{~g} \mathrm{~N}$ was applied through 10 biweekly applications of calcium nitrate beginning on 20 May 2005. Each data point is the average of nine replications of five seedlings. Averages for each time point were statistically analyzed by analysis of variance with mean separation by Duncan's multiple range test. Means within date followed by the same letter are not significantly different $(1 \mathrm{~mm}=0.0394$ inch; $1 \mathrm{~g}=0.0353 \mathrm{oz})$.

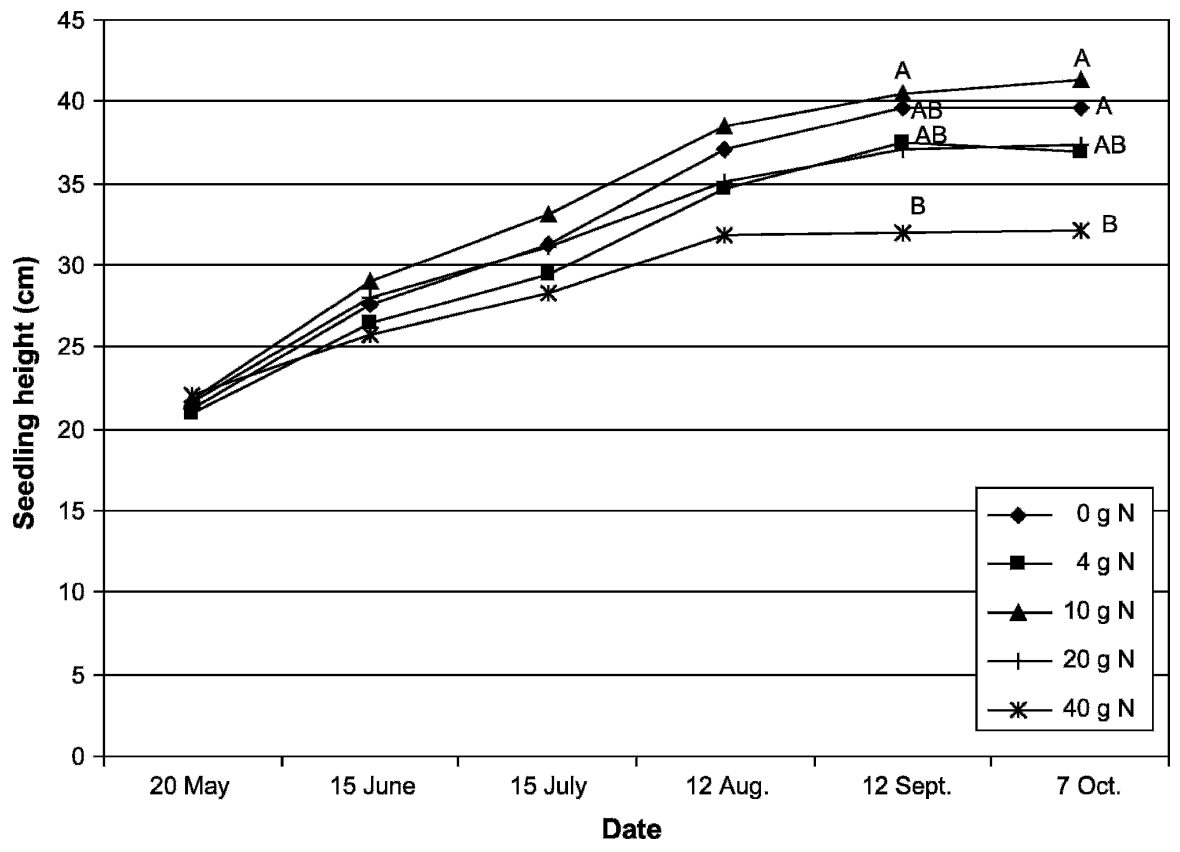

Fig. 2. Effect of nitrogen $(\mathrm{N})$ fertigation on first-year pecan seedling height. A total of $0,4,10,20$, or $40 \mathrm{~g} \mathrm{~N}$ was applied through 10 biweekly applications of calcium nitrate beginning on 20 May 2005. Each data point is the average of nine replications of five seedlings. Averages for each time point were statistically analyzed by analysis of variance with mean separation by Duncan's multiple range test. Means within date followed by the same letter are not significantly different $(1 \mathrm{~cm}=0.3937$ inch; $1 \mathrm{~g}=0.0353 \mathrm{oz})$.

nurseryman than stem caliper because this is the region that is cut for whip grafting. However, to measure root roots. Because these two measurements are so highly correlated, stem caliper is probably sufficient to use in future studies.

Seedlings in this experiment continued to increase in height for a period of at least 3 to 4 months from emergence, depending on treatments, which is greater than the 1 to 2 months listed by Worthington (1997). This increase in growing period may be explained by the abundant moisture that was supplied to the seedlings or the cooler soil provided by the white plastic. In other experiments, we have found pecan seedlings to grow better under white plastic than on bare ground (unpublished data). Root caliper of dormant seedlings averaged $\approx 2.0 \mathrm{~cm}$ across treatments (data not presented), and this is sufficiently large enough for whip grafting. Patch budding, however, would take place in the summer and stem caliper was not large enough for this to be accomplished in the first year.

Leaf element analysis was conducted on leaves sampled on 15 July and on 7 Oct., 2 weeks after the fourth and tenth $\mathrm{N}$ fertigations, respectively. The July sampled leaves showed no significant differences in $\mathrm{N}$ concentration (Table 2), but $\mathrm{N}$ fertigation produced a modest increase in leaf $\mathrm{N}$ concentration by the end of the season (Table 3 ). The maximum average $\mathrm{N}$ concentration of the leaf samples was $2.68 \%$, which is near the lower limit of the sufficiency range given for mature pecan trees (Wells and Harrison, 2006). Sparks (1968) found that 1-year-old pecan seedlings grew best when leaf $\mathrm{N}$ concentration was in the range of $2.6 \%$ to $2.9 \%$. The range of $2.2 \%$ to $2.6 \%$, which nearly all of these samples fell into, was considered the range of hidden deficiency. In contrast to this study, where growth suppression occurred with a leaf $\mathrm{N}$ concentration of $2.68 \%$, Sparks and Baker (1975) did not see suppression of seedling growth until leaf $\mathrm{N}$ concentration exceeded $2.9 \%$. However, it is difficult to compare these experiments because leaf age varied between the experiments and this influences $\mathrm{N}$ concentration (Hammar and Hunter, 1949).

Calcium concentration increased caliper, soil must be removed from around the base of the plant and this is labor-intensive and may damage in the treatments receiving high rates of fertigation by the second sampling 


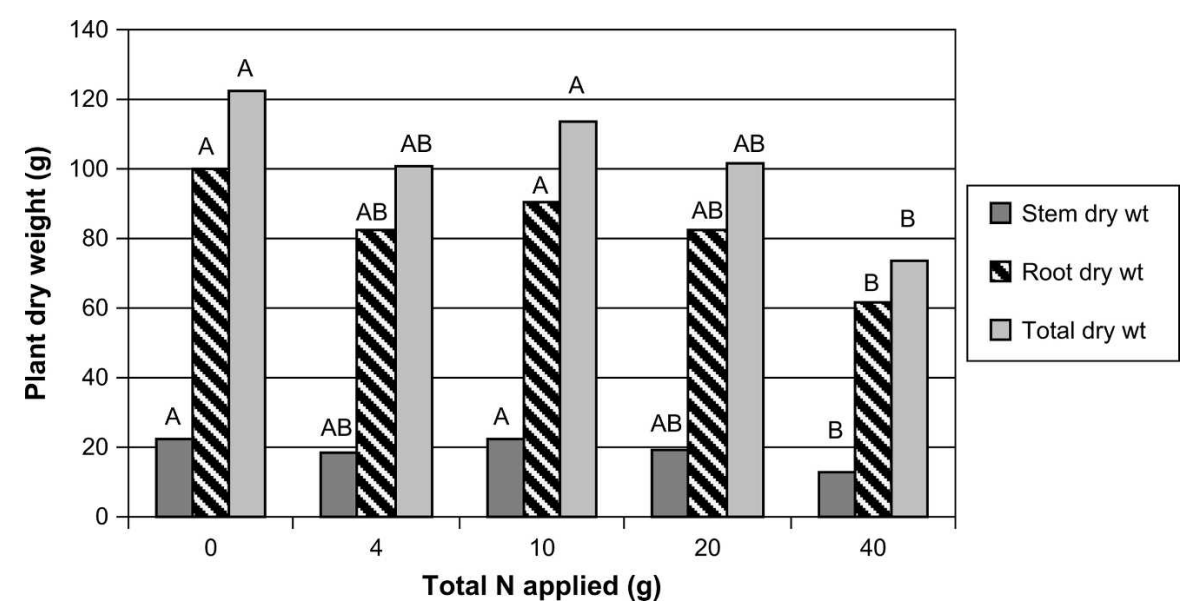

Fig. 3. Effect of nitrogen $(\mathrm{N})$ fertigation on first-year pecan seedling stem, root, and total dry weight. A total of $0,4,10,20$, or $40 \mathrm{~g} \mathrm{~N}$ was applied through 10 biweekly applications of calcium nitrate beginning on 20 May 2005. Each data point is the average of nine replications of five seedlings. Averages among fertigation levels for each growth measurement were statistically analyzed by analysis of variance with mean separation by Duncan's multiple range test. Means within a weight series followed by the same letter are not significantly different $(1 \mathrm{~g}=\mathbf{0 . 0 3 5 3} \mathrm{oz})$.

Table 1. Pearson correlation coefficients between growth measurements of first-year pecan seedlings.

\begin{tabular}{|c|c|c|c|c|c|c|}
\hline & $\mathbf{H t}^{\mathbf{z}}$ & $\begin{array}{c}\text { Stem } \\
\text { caliper }^{\mathrm{z}}\end{array}$ & $\begin{array}{c}\text { Root } \\
\text { caliper }^{y}\end{array}$ & $\begin{array}{c}\text { Stem } \\
\text { dry } w t^{y}\end{array}$ & $\begin{array}{c}\text { Root } \\
\text { dry } w^{y}{ }^{y}\end{array}$ & $\begin{array}{c}\text { Total } \\
\text { dry } w t^{y}\end{array}$ \\
\hline \multicolumn{7}{|l|}{ Height $^{z}$} \\
\hline Stem caliper ${ }^{\mathrm{z}}$ & $0.90^{*}$ & & & & & \\
\hline Root caliper $^{\mathrm{y}}$ & $0.89 *$ & $0.95^{*}$ & & & & \\
\hline Stem dry $w t^{\mathrm{y}}$ & $0.94^{*}$ & $0.93^{*}$ & $0.92 *$ & & & \\
\hline Root dry $\mathrm{wt}^{\mathrm{y}}$ & $0.86^{*}$ & $0.87^{*}$ & $0.89^{*}$ & $0.90^{*}$ & & \\
\hline Total dry $w t^{y}$ & $0.89 *$ & $0.90 *$ & $0.92 *$ & $0.94^{*}$ & $1.00 *$ & \\
\hline
\end{tabular}

${ }^{\mathrm{z}}$ Measured on 7 Oct. 2005

${ }^{\mathrm{y}}$ Measured on 7 Jan. 2006

* Significant at $P \leq 0.001$

period (Table 3 ). This is not surprising given the high rates of $\mathrm{CaNO}_{3}$ that were applied. Sparks (1986) found that pecan seedling growth was stimulated by leaf calcium levels up to $1.7 \%$, and all treatments in this experiment fell below this level. Magnesium concentration of leaves declined with increasing rates of fertigation (Tables 2 and 3 ). The application of high rates of nitrate may have caused magnesium in the soil to form soluble salts that were leached from the root zone; in addition, high levels of calcium can inhibit magnesium uptake (Loide, 2004). The lower threshold for magnesium leaf concentration of mature pecan trees is $0.30 \%$ (Sparks, 1976); thus, the highest fertigation rate may have resulted in a slight magnesium deficiency in the seedlings by the end of the season.

Leaf concentration of boron increased with increasing fertigation rates (Tables 2 and 3 ). Optimum been associated with a potassium deficiency in pecan (Gammon and Sharpe, 1959; Sparks and Baker, 1975). In this experiment, leaf potassium in the second sampling period was lower than the $0.75 \%$ threshold used for bearing trees in Georgia. However, there was no difference in potassium levels among the treatments, nor were there significant differences in the $\mathrm{N}: \mathrm{K}$ ratio (data not shown), and the reduction in potassium concentration may have been influenced by the late timing of the second sampling period. Therefore, it does not seem likely that the reduction in growth incited by the high rate of $\mathrm{N}$ fertigation is related to a potassium deficiency.

Unlike some tree species that alter relative dry weight distribution between roots and stems with $\mathrm{N}$ fertigation (Larimer and Struve, 2002), relative weights of pecan seedling roots and stems remained remarkably stable at all $\mathrm{N}$ fertigation levels with stems accounting for $\approx 18 \%$ of the plant dry weight across all treatments. This indicates a low probability of altering the root:stem ratio as is also suggested by the high correlations between top and root growth (Table 1). An inability to markedly increase growth rates or alter root:stem ratios in a nutrientrich environment is characteristic of a stress tolerator species (Larimer and Struve, 2002). This growth pattern is vital to pecan in its native sites, which are characterized by abundant moisture in the spring followed by a dry summer with a lowering water table (Sparks, 2002). Thus, in a semiarid environment, a dominant taproot is vital because a lack of surface water often limits the growth of shallowrooted species, and pecan is the climax vegetation (Sparks, 2002). However, in more humid sites, pecan growth is often restricted by the vigorous growth of more competitive sympatric species. Because pecan is a phreatophyte (a plant that characteristically roots to the water table), accelerating the first-year growth may be difficult unless the water table of the planting site is altered (Tilt et al., 1994).

Collectively, these data indicate that there is no benefit in terms of seedling growth of applying additional $\mathrm{N}$ by fertigation to pecan seedlings during the first season. Additionally, 
Table 2. Effect of four applications of nitrogen $(\mathrm{N})$ fertigation on elemental concentration of seedling pecan leaves sampled on 15 July 2005.

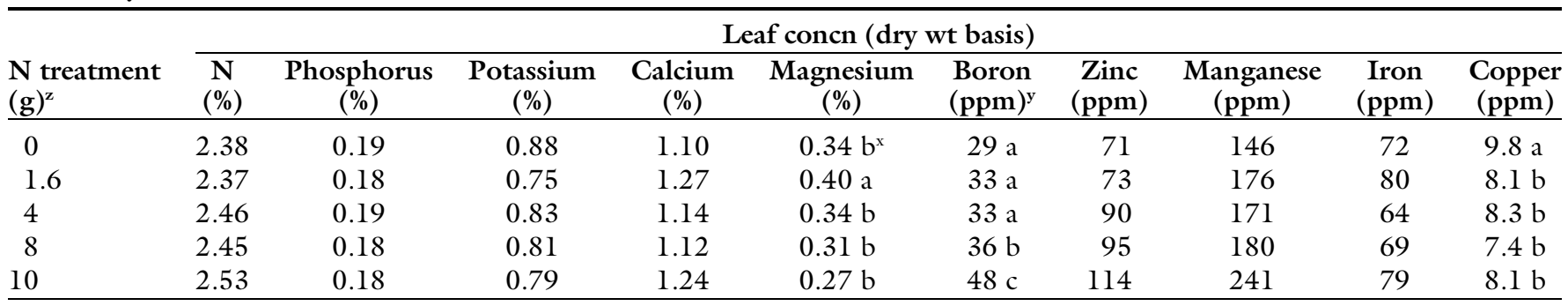

${ }^{2}$ Total amount of $\mathrm{N}$ applied per seedling after four biweekly fertigation applications beginning on 20 May 2005 . Leaf samples were taken on 15 July 2005,2 weeks after the fourth fertigation; $1 \mathrm{~g}=0.0353 \mathrm{oz}$.

${ }^{\mathrm{y}} 1 \mathrm{ppm}=1 \mathrm{mg} \cdot \mathrm{kg}^{-1}$.

xAny two means within a column not followed by the same letter are significantly different based on analysis of variance with mean separation by Duncan's multiple range test.

Table 3. Effect of 10 applications of nitrogen $(\mathrm{N})$ fertigation on elemental concentration of seedling pecan leaves sampled on 7 Oct. 2005.

\begin{tabular}{|c|c|c|c|c|c|c|c|c|c|c|}
\hline \multirow[b]{2}{*}{$\begin{array}{l}\text { N treatment } \\
(\mathrm{g})^{\mathrm{z}}\end{array}$} & \multicolumn{10}{|c|}{ Leaf concn (dry wt basis) } \\
\hline & $\begin{array}{c}\mathrm{N} \\
(\%)\end{array}$ & $\begin{array}{c}\text { Phosphorus } \\
(\%)\end{array}$ & $\begin{array}{c}\text { Potassium } \\
(\%)\end{array}$ & $\begin{array}{c}\text { Calcium } \\
(\%)\end{array}$ & $\begin{array}{c}\text { Magnesium } \\
(\%)\end{array}$ & $\begin{array}{l}\text { Boron } \\
(\mathrm{ppm})^{\mathrm{y}}\end{array}$ & $\begin{array}{c}\text { Zinc } \\
(\mathrm{ppm})\end{array}$ & $\begin{array}{c}\text { Manganese } \\
(\mathrm{ppm})\end{array}$ & $\begin{array}{c}\text { Iron } \\
(\mathrm{ppm})\end{array}$ & $\begin{array}{c}\text { Copper } \\
\text { (ppm) }\end{array}$ \\
\hline 4 & $2.52 \mathrm{bc}$ & 0.15 & 0.68 & $1.36 \mathrm{ab}$ & $0.37 \mathrm{ab}$ & $40 \mathrm{a}$ & 84 & 204 & 75 & 4.1 \\
\hline 10 & $2.40 \mathrm{ab}$ & 0.14 & 0.68 & $1.34 \mathrm{ab}$ & $0.32 \mathrm{~b}$ & $54 \mathrm{ab}$ & 104 & 292 & 73 & 4.6 \\
\hline 20 & $2.59 \mathrm{c}$ & 0.14 & 0.63 & $1.38 \mathrm{ab}$ & $0.29 \mathrm{~b}$ & $65 \mathrm{bc}$ & 105 & 319 & 67 & 4.2 \\
\hline
\end{tabular}

${ }^{z}$ Total amount of $\mathrm{N}$ applied per seedling over the course of 10 biweekly fertigation applications beginning on 20 May 2005 . Leaf samples were taken 2 weeks after the tenth fertigation on 7 Oct. $2005 ; 1 \mathrm{~g}=0.0353 \mathrm{oz}$.

y $1 \mathrm{ppm}=1 \mathrm{mg} \cdot \mathrm{kg}^{-1}$.

×Any two means within a column not followed by the same letter are significantly different based on analysis of variance with mean separation by Duncan's multiple range test.

as reported by Sparks and Baker (1975), the higher rates of $\mathrm{N}$ were detrimental to the growth of the seedlings. The $10 \mathrm{~g}$ of $\mathrm{N}$ rate produced the tallest seedlings, but this treatment was not significantly different from the $0 \mathrm{~g}$ of $\mathrm{N}$ rate nor was the caliper of this treatment larger than the $0 \mathrm{~g} \mathrm{~N}$ rate. It appears that the application of $50 \mathrm{lb} /$ acre of $10 \mathrm{~N}-4.4 \mathrm{P}-8.3 \mathrm{~K}$ before planting, plus native soil fertility, supplied adequate $\mathrm{N}$ for the first year of seedling growth.

\section{Literature cited}

Gammon, N., Jr. and R. Sharpe. 1959. Effect of five years of differential fertilization with nitrogen and potassium on the soil nutrients and on mineral composition of Curtis pecan leaves. Proc. Southeastern Pecan Growers Assn. 46:53-63.

Hammar, H. and J. Hunter. 1949. Influence of fertilizer treatment on the chemical composition of Moore pecan leaves during nut development. Plant Physiol. 24:16-30.

Hammar, H., C. Smith, and A. Alben. 1953. Boron uptake as a criterion of the root spread of the pecan trees. Proc. Amer. Soc. Hort. Sci. 62:131-134.

Harris, R.W. 1992. Root-shoot ratios. J. Aboriculture 18:39-42.
Kormanik, P.P., S.S. Sung, and T.L. Kormanik. 2003. Growing, selecting, and establishing 1-0 Quercus rubra and Q. alba seedlings for rapid growth and early acorn production on forested lands in the southeastern United States. Intl. Oaks 15:119-125.

Larimer, J. and D. Struve. 2002. Growth, dry weight, and nitrogen distribution of red oak and 'Autumn Flame' red maple under different fertility levels. J. Environ. Hort. 20:28-35.

Loide, V. 2004. About the effect of the contents and ratios of soil's available calcium, potassium, and magnesium in liming of acid soils. Agr. Res. 2:71-82.

Plank, C. 1988. Plant analysis handbook for Georgia. Georgia Coop. Ext. Serv. Athens.

Sparks, D. 1968. Some effects of nitrogen on young pecan trees. Proc. Southeastern Pecan Growers Assn. 61:93-102.

Sparks, D. 1976. Magnesium nutrition and the pecan-a review. Pecan South 3:264-267.

Sparks, D. 1986. Effect of calcium on pecan growth and nutrition. HortScience 21:332.

Sparks, D. 2002. Rainfall governs pecan stand homogeneity in native, wild habitats. J. Amer. Soc. Hort. Sci. 127:860-868.

Sparks, D. 2005. Adaptability of pecan as a species. HortScience 40:1175-1189.
Sparks, D. and D. Baker. 1975. Growth and nutrient response of pecan seedlings, Carya illinoensis Koch., to nitrogen levels in sand culture. J. Amer. Soc. Hort. Sci. 100:392-399.

Tilt, K., W. Goff, D. Williams, R. Shumack, and J. Olive. 1994. Improved growth of pecan and ornamental pear trees in containers with water holding reservoirs. HortScience 29:649-651.

U.S. Dept. Agr. 2005. Noncitrus fruits and nuts 2004 summary. U.S. Dept. Agr. National Agricultural Statistics Service, Fr Nt 1-3 (05).

Wells, M.L. and K.A. Harrison. 2006. Cultural management of commercial pecan orchards. Univ. Georgia Coop. Ext. Bul. 1304.

White, A.W., Jr. 1982. Effects of topsoil-subsoil fertilizer and lime amendments on top and root growth of 'Stuart' pecan seedlings in a simulated Norfolk soil profile. HortScience 17: 380-381.

Worley, R.E. 2001. Compendium of pecan production and research. Edward Brothers, Ann Arbor, MI.

Worthington, J.W. 1997. Nursery operations, p. XI, 3-6. In: G.R. McEachern and L.A. Stein (eds.). 1997 Texas pecan handbook. Texas Agr. Ext. Serv., College Station. 